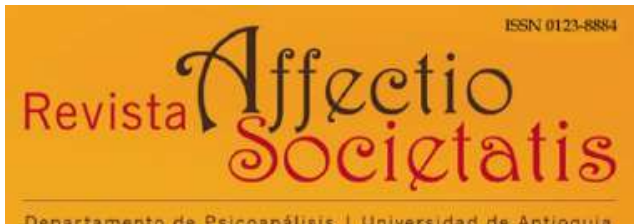

Departamento de Psicoanálisis I Universidad de Antioquia

Revista Affectio Societatis

Departamento de Psicoanálisis

Universidad de Antioquia

revistaaffectiosocietatis@udea.edu.co

ISSN (versión electrónica): 0123-8884

Colombia

2020

Jamile Luz Morais Monteiro, Roseane Freitas Nicolau

Um resgate histórico da psicossomática: de Freud aos pósfreudianos

Revista Affectio Societatis, Vol. 17, N. ${ }^{\circ} 32$, enero-junio de 2020

Art. \# 3 (pp. 59-85)

Departamento de Psicoanálisis, Universidad de Antioquia Medellín, Colombia 


\title{
UM RESGATE HISTÓRICO DA PSICOSSOMÁTICA: DE FREUD AOS PÓS-FREUDIANOS
}

\author{
Jamile Luz Morais Monteiro ${ }^{1}$ \\ Universidade Federal do Tocantins (UFT), Brasil \\ jamile@uft.edu.br \\ ORCID: 0000-0002-1695-2191 \\ Roseane Freitas Nicolau² \\ Universidade Federal do Pará (UFPA), Brasil \\ rfnicolau@uol.com.br \\ ORCID: 0000-0002-6988-943X \\ DOI: 10.17533/udea.affs.v17n32a03
}

\section{Resumo}

Trata-se de um recorte da dissertação de mestrado "Corpo, feminino e subjetivação: uma análise a partir de sujeitos com lúpus eritematoso sistêmico". Objetiva sustentar a presença da psicanálise desde os primórdios dos estudos sobre psicossomática, através de um percurso histórico sobre o tema, delineando a origem deste campo de saber, bem como as principais elaborações teórico-conceituais resultantes da interlocução entre a medicina e a psicanálise. Considerando a influência de Freud para a inauguração do campo de saber denominado "psicossomático", destacam-se

1 Psicóloga e Psicanalista. Doutora em Psicologia Social, Pontifícia Universidade Católica de São Paulo. Mestre em Psicologia, Universidade Federal do Pará (UFPA). Especialista em Oncologia em modalidade de Residência Multiprofissional em Saúde, Hospital Universitário de João de Barros Barreto (нUјвв). Professora do curso de Psicologia da Universidade Federal do Tocantins (UFT).

2 Psicóloga e Psicanalista. Doutora em Sociologia, Universidade Federal do Ceará. Professora Associada da Faculdade de Psicologia e do Programa de Pós-Graduação em Psicologia da Universidade Federal do Pará (UFPA), coordenadora do grupo de pesquisa "Laboratório de clínica do sujeito: sintoma, corpo e instituição", cadastrado no CNPQ, e do GT da ANPEPP Psicanálise, política e clínica. Membro da Escola de Psicanálise Letra Freudiana. 
principalmente as produções de Groddeck, Ferenczi, Alexander e Marty.
Palavras-chave: psicossomática; psicanálise; medicina.

\section{UN RESCATE HISTÓRICO DE LA PSICOSOMÁTICA: DE FREUD A LOS POSFREUDIANOS}

\section{Resumen}

Este es un fragmento del trabajo de maestría "Cuerpo, femenino y subjetivación: un análisis a partir de sujetos con lupus eritematoso sistémico". El objetivo es sostener la presencia del psicoanálisis desde los inicios de los estudios sobre la psicosomática a través de un recorrido histórico sobre el tema, esbozando el origen de este campo del saber, así como las principales elaboraciones teórico-con- ceptuales que resultan de la interlocución entre la medicina y el psicoanálisis. Considerando la influencia de Freud para la inauguración del campo del saber llamado "psicosomática", destacan principalmente las producciones de Groddeck, Ferenczi, Alexander y Marty.

Palabras clave: psicosomática; psicoanálisis; medicina.

\section{A HISTORIC RESCUE OF PSYCHOSOMATICS: FROM FREUD TO THE POST-FREUDIANS}

\section{Abstract}

This is a fragment of the master's work "Body, Feminine and Subjectivation: An Analysis from Subjects with Systemic Lupus Erythematosus". The objective is to support the presence of psychoanalysis from the beginning of the studies on psychosomatics through a historical journey on the topic, outlining the origin of this field of knowledge, as well as the main theoretical-conceptual elabora- tions that result from the dialogue between medicine and psychoanalysis. Considering Freud's influence over the inauguration of the field of knowledge called "psychosomatics", the productions of Groddeck, Ferenczi, Alexander, and Marty stand out mainly.

Keywords: psychosomatics; psychoanalysis; medicine. 


\section{UNE RESTITUTION HISTORIQUE DE LA PSYCHOSOMATIQUE : DE FREUD AUX POSTFREUDIENS}

\section{Résumé}

Cet article est issu d'un mémoire de master intitulé "Corps, féminin et subjectivation : une analyse à partir de sujets atteints de lupus érythémateux systémique». Le but est de confirmer la présence de la psychanalyse depuis le début des études sur la psychosomatique à travers un parcours historique sur le sujet, en esquissant $l^{\prime}$ origine de ce domaine du savoir, ainsi que les principales élabo- rations théoriques-conceptuelles surgies du dialogue entre la médecine et la psychanalyse. L'influence de Freud dans les débuts de ce domaine de la «psychosomatique» est considérée, ainsi que les importantes productions de Groddeck, Ferenczi, Alexander et Marty.

Mots-clés : psychosomatique ; psychanalyse ; médecine. 
Este artigo tem como objetivo apresentar a heterogeneidade de teorias sobre o que se instituiu como "psicossomática", a partir de um denominador comum: Freud. Através de uma revisão bibliográfica pela psicanálise, objetivamos realizar um resgate histórico acerca da psicossomática partindo de Freud até os pós-freudianos, especificamente, a saber: George Groddeck, Sándor Ferenczi, Franz Alexander, Helen Dunbar, Pierre Marty e Michel de M'Uzan. Quanto ao psicanalista francês Jacques Lacan, embora reconhecendo a importância de suas contribuições ao campo de investigação concernente à "psicossomática", considerando principalmente o que nomeou de "falha epistemossomática" (Lacan, 1966/2001) a fim apontar o "hiato sobre a relação da medicina com o corpo" (Rinaldi, Nicolau \& Pitanga, 2013, p. 95), não pretendemos desenvolver suas propostas por compreendermos que merecem um trabalho em separado.

Para tanto, percorrer a história do campo de saber denominado de "psicossomática" requer salientar que a origem desta expressão não acompanha o próprio desenvolvimento histórico deste campo. A introdução do termo "psicossomática" se deve ao professor de psiquiatria de Leipzig, Johann Heinroth (1773-1843), que descreveu as fontes "psicossomáticas" da insônia, em 1818. O então psiquiatra participou de um movimento profícuo no terreno da psiquiatria alemã, no início do século XIX. Nessa época, os psiquiatras dividiam-se em duas escolas: uma priorizava os aspectos psíquicos sobre o adoecer mental; e a outra defendia a predominância dos fatores orgânicos no desencadeamento das afecções mentais. Heinroth foi um psiquiatra que integrou o primeiro grupo, pois acreditava que o psíquico interferia de modo determinante para o surgimento da patologia mental e, neste sentido, considerando a origem do termo "psicossomática", ele foi um personagem marcante nesse contexto (Shorter, 2012).

Por outro lado, Freud (1996/1895[1894]) também debruçou-se sobre os fenômenos corporais sem etiologia orgânica aparente, através do que chamou de "neuroses atuais". Freud as diferenciou especialmente das conversões histéricas, caracterizadas por perturbações sexuais indiretas, resultantes de processos psíquicos inconscientes e infantis. Já os sintomas das "neuroses atuais" (tais como dispepsia, insônia, palpitações, vertigens, cefaléias, neuralgias, pressão torácica, 
ondas de frio e calor pelo corpo, tremores nas extremidades e formigamentos), foram concebidos por ele como afecções sexuais diretas (Freud, 1996/1895[1894]).

Assim, embora Freud tenha utilizado a expressão "psicossomática" somente uma vez, em uma carta dirigida ao médico, professor de Heidelberg, Viktor Von Weizsäcker (1886-1957), com efeito, ele contribuiu significativamente, através de suas formulações sobre as "neuroses atuais", para o surgimento de um campo de saber heterogêneo sobre as afecções corporais sem etiologia orgânica definida. Consta em Quintella (2005) que em decorrência da interlocução entre os saberes médico e psicanalítico, o estudo da psicossomática "passou a se constituir como uma importante vertente da psicanálise, ou pelo menos como investigação importante em permanente diálogo com esta" (Quintella, 2005, p. 5). O autor ainda ressalta que esta interlocução teve início com o próprio Freud que, ao criticar a noção mecanicista e organicista do corpo e das enfermidades orgânicas, deu um passo significativo para o surgimento de um campo de investigação sobre a "psicossomática".

No entanto, apesar de localizarmos um território de pesquisa bem definido sobre "psicossomática", é importante lembrar que a expressão "psicossomática", justo por guardar consigo um forte parentesco com a psicanálise, foi negligenciada a partir da publicação da terceira versão do Manual Estatístico e Diagnóstico dos Transtornos Mentais (DSM-III), cunhado pela Associação de Psiquiatria Americana (APA), tal como afirma Shorter (2012):

Esforços oficiais da Associação de Psiquiatria Americana para explicar a noção de doença psicossomática produziram alguma confusão. A própria palavra psicossomática não apareceu no manual diagnóstico da APA de 1980, que em vez disso se utilizou da amorfa categoria "fatores psicológicos afetando a condição física" (DSM-III, 1980). Além do mais, o DSM-III planejou uma lista de diagnósticos "somatoformes" específicos, tais como transtornos de somatização, o transtorno conversivo e o transtorno doloroso psicogênico, que se sobrepunham e eram difíceis de se distinguir um do outro (...) À medida que as categorias diagnósticas oficiais para lidar com a doença psicossomática se provavam insatisfatórias, muitos clínicos 
voltaram-se para um conceito fora da nosologia oficial: "somatização" como um processo. (Shorter, 2012, p. 767).

A história demonstra que o esforço da Associação de Psiquiatria Americana para explicar as doenças psicossomáticas desconsiderando a contribuição da psicanálise, deixou de fora toda uma perspectiva teórica fecunda no estudo dessas doenças. Freud está presente nesse estudo, particularmente com as elaborações sobre as "neuroses atuais", que representaram um papel primordial para o desenvolvimento deste campo da "psicossomática".

\section{Retomando contribuições do campo da psicossomática}

Retomar as elaborações teórico-conceituais resultantes da interlocução entre a medicina e a psicanálise impõe-se como uma tarefa primordial. Verifica-se no DSM-I e no DSM-II uma forte influência da psicanálise nas descrições nas categorias mentais. Este fato, por conseguinte, possibilitava um diálogo entre as duas disciplinas e, nesse sentido, o estudo sobre as afecções ditas "psicossomáticas" localizava-se na interlocução entre os saberes médico e psicanalítico. O DSM-I, por exemplo, sofreu considerável interferência do psiquiatra Adolf Meyer (1866-1950), o qual, embora não tenha seguido a metapsicologia freudiana, reconhecia a importância de colher a história detalhada do doente. No sistema diagnóstico proposto por ele, era possível encontrar categorias de extração psicodinâmica, especialmente no que concernia a distinção entre neurose e psicose. Em seguida, o DSM-II, com algumas pequenas diferenças em relação à primeira versão, caminhou no sentido de manter o diálogo com a teoria psicodinâmica (Dunker \& Kyrillos Neto, 2011).

Já o DSM-III, como mencionamos, surgiu com uma proposta operacional, ateórica e pragmática, expurgando toda e qualquer teoria psicopatológica, inclusive a psicanalítica, do manual. Sob a rubrica do termo "transtorno", essa terceira versão negligenciou o arcabouço teórico e heterogêneo que caracterizava o campo de investigação sobre as patologias psicossomáticas. Subtraiu-se o prefixo "psico" da expressão "psicossomática" e, a partir de então, a palavra "somatiza- 
ção", cunhada pelo psicanalista vienense Wilhelm Steckel (1868-1940) passou a vigorar para representar a conversão histérica e outras lesões que acometiam o corpo sem etiologia orgânica aparente (Shorter, 2012). Sobre a abolição do vocabulário psicanalítico no DSM-III, afirmam Berrios e Mumford (2012):

O termo "histeria" foi abandonado e uma nova síndrome, "transtorno de somatização", foi criada. Esta era definida no DSM-III como "um transtorno crônico, mas flutuante, que começa cedo na vida, e é caracterizada por queixas somáticas recorrentes e múltiplas para as quais é buscada atenção médica, mas que não são aparentemente causadas por qualquer doença física. (Berrios e Mumford, 2012, p. 751).

Nessa direção, a psicanálise foi não apenas excluída do manual, mas também erroneamente interpretada, pois, como ressaltado, o mesmo fez todo um esforço de distinguir as "neuroses atuais" das conversões histéricas. Já o DSM-IV e o DSM-V, deram continuidade ao projeto do DSM-III. Na quarta versão, permaneceu à expressão "Transtorno Somatoforme" ou, dito de outra maneira, "Transtorno de Sintomas Somáticos e Transtornos Relacionados", caracterizado pela presença de sintomas físicos que sugerem uma condição médica geral e que não são plenamente explicados por essa condição (APA, 2002).

Na atual e quinta versão do manual, considera-se como critério crucial para o diagnóstico do transtorno a "presença de sinais e sintomas somáticos positivos (sintomas somáticos perturbadores associados a pensamentos, sentimentos e comportamentos anormais em resposta a esses sintomas)" (APA, 2014, p. 309), ao invés somente da ausência de uma explicação médica para sintomas somáticos. Entre as afecções que faziam parte deste transtorno, no DSM-IV, destacavam-se: a psoríase, a dermatite, a fibromialgia, o lúpus, alergias de modo geral resistentes ao tratamento, como urticárias, a síndrome do intestino irritável, entre outras.

De todo modo, Freud foi fundamental para todos os campos de investigação em psicanálise e, através de suas formulações sobre o aparelho psíquico e a dinâmica inconsciente, é que autores como Ge- 
orge Groddeck, Sándor Ferenczi, Franz Alexander, Helen Dunbar, Pierre Marty e Michel de M'Uzan, puderam teorizar em torno dessas enfermidades que aparecem no corpo sem etiopatogenia determinada. Na era dominada pelo discurso do DSM, é importante resgatar as principais elaborações em torno da psicossomática, hoje ignoradas neste manual. Vejamos as contribuições desses autores.

\section{Groddeck e as manifestações do "Isso"}

O médico alemão George Walter Groddeck (1866-1934) é considerado o pai da psicossomática e defendeu radicalmente a psicologização do biológico. Contemporâneo de Freud, tornou-se membro da Associação Psicanalítica de Berlim, porém, depois de um curto período, rejeitou a teoria freudiana para construir uma teoria própria.

Em seu livro intitulado Estudos psicanalíticos sobre psicossomática, Groddeck (1992/1920) salientou que "doença e saúde são formas de expressão de uma só vida. A doença não vem de fora, não é um inimigo, mas sim uma criação do organismo, do Isso" (Groddeck, 1992/1920, p. 97).

Nessa linha de pensamento, todas as doenças trariam consigo um sentido, por si só, inconsciente, o que agregaria para ele um valor de extrema importância: "Não obstante, a questão do sentido da doença tem um valor, um valor prático, um valor para o médico, entendendo por médico todo aquele trata" (Groddeck, 1997/1917, p. 97). Ao considerar a doença como algo de intrínseco ao próprio sujeito, ela guardaria um sentido singular em sua constituição, podendo estar sujeita (assim como nas psiconeuroses), a um trabalho de interpretação via tratamento analítico: o ficar doente haveria de ter um sentido.

Partindo da idéia conforme a qual "eu sou vivido por Isso" (Groddeck, 1997/1917, p. 29), Groddeck ressaltou que as ações do ser humano, de um jeito ou de outro, estariam sempre vinculadas ao "Isso": 
Acredito que o homem é vivido por algo desconhecido. Existe nele um "Isso", uma espécie de fenômeno que comanda tudo o que ele faz e tudo o que lhe acontece. A frase "Eu vivo..." é verdadeira em parte; ela expressa apenas uma pequena parte dessa verdade fundamental: o ser humano é vivido pelo Isso. (Groddeck, 1997/1917, p. 9).

No momento em que atribuiu ao "Isso" o mesmo patamar que o inconsciente, e estudando as doenças somáticas através da análise em diversos de seus pacientes, Groddeck (1997/1917) chegou à conclusão, por exemplo, que uma fratura ou qualquer afecção nos membros inferiores significaria que o "Isso acha melhor não andar temporariamente" (Groddeck, 1997/1917, p. 101). Sendo assim, podemos considerar que, para Groddeck, toda doença orgânica era "psicossomática", na medida em que, por ser uma formação do inconsciente, ela guardariam um sentido que só poderia ser interpretado via análise.

Nessa perspectiva, Quintella (2005) critica a teoria de Groddeck, dizendo que este, ao colocar as doenças psicossomáticas no mesmo nível das psiconeuroses, de certo modo, negligencia a abordagem freudiana das "neuroses atuais", as quais, por não possuírem em seu funcionamento uma articulação com a esfera psíquica, não poderiam, portanto, serem consideradas como uma formação do inconsciente. Contudo, ao mesmo tempo em que critica tal abordagem, o autor supracitado também nos coloca que as formulações de Groddeck acabaram rendendo a Freud importantes contribuições em um segundo momento de sua teoria.

Na mesma direção, Casetto (2006) nos fala que se levarmos a cabo as teorizações desse "analista selvagem", implicaríamos o Isso até mesmo "nos acidentes que nos acontecem" (p. 124), pois as ideias de Groddeck, na medida em que sempre estiveram voltadas para a decifração dos sintomas, acabaram não propondo ações no sentido de desenvolver dispositivos clínicos para lidar com o poder que ao "Isso" atribuía na eclosão de determinadas doenças. Foi por estas e outras razões que, conforme veremos a seguir, Groddeck será fortemente criticado por Ferenczi, o qual, por também ter estudado as 
influências do psiquismo no adoecimento orgânico, formulou ideias próprias a respeito.

\section{Ferenczi: as patoneuroses e as neuroses de órgão}

O médico e psicanalista Sándor Ferenczi (1873-1933) criticou de forma ferrenha as formulações de Groddeck. Em seu texto chamado George Groddeck: O explorador de almas, Ferenczi (1993/1921) se referiu à Groddeck reconhecendo abertamente que se enganara ao enfurecer-se contra o criador da psicanálise - o que é ainda mais excepcional - desvendou coram público seu próprio inconsciente ao indicar uma tendência que o impeliria, por pura inveja, a fazer-se adversário de Freud (Ferenczi, 1993/1921, p. 131). Apontou a falta de rigor teórico em suas formulações, deixando claro que o médico negligenciou não só o próprio do método psicanalítico, mas também qualquer saber científico. Sobre a teoria de Groddeck, Ferenczi (1993/1921) salienta:

Muitos de seus artigos pareciam apresentar alguma semelhança com determinadas teses da psicanálise. Entretanto, no começo, Groddeck atacou a escola de Freud, como atacaria todas as escolas em geral. Finalmente, o seu fanatismo pela verdade mostra-se ainda mais forte do que a sua aversão por todo saber escolástico: reconheceu abertamente que se enganara ao enfurecer-se contra o criador da psicanálise e - o que é ainda mais excepcional - desvendou coram público seu próprio inconsciente ao indicar uma tendência que o impeliria, por pura inveja, a fazer-se adversário de Freud. (Ferenczi, 1993/1921, p. 131).

Para Ferenczi, ao inserir sentido às afecções de seus pacientes, Groddeck só poderia ter conseguido bons resultados graças não à psicanálise, mas sim através "de um poder de uma sugestão de uma personalidade única excepcional” (Ferenczi, 1993/1921, p. 132).

Ao mesmo tempo em que criticou as teorias groddeckeanas, $\mathrm{Fe}-$ renczi (1993/1921), sendo mais fiel ao pensamento freudiano, também construiu consideráveis formulações acerca das relações pre- 
sentes entre o adoecimento orgânico e o psiquismo. Através de suas experiências como médico em um hospital militar durante a Primeira Guerra, Ferenczi pôde formular toda uma teoria sobre o adoecer orgânico a partir das neuroses traumáticas. Em "Psicanálise das Neuroses de Guerra", Ferenczi (1993/1921), visando explicar a etiologia dessas neuroses, chama atenção para o fato de que uma teoria puramente organicista e mecanicista não daria conta de explicar o que, até então, estava acontecendo durante a guerra. Afirmou que, neste período, a eclosão em massa de neuroses graves levou não só ele, como também vários neurologistas, a recorrerem ao fator psíquico como causa de certas patologias. Assim, criticou os neurologistas que durante algum tempo resistiram à psicanálise:

Os neurologistas não podem escapar à censura de terem menosprezado por muito tempo os trabalhos inovadores de Breuer e Freud sobre o determinismo psíquico de numerosos distúrbios nervosos e de terem esperado pela pavorosa experiência de guerra para ficar um pouco mais bem informados. Ora, existe há mais de 20 anos uma ciência, a psicanálise, à qual muitos investigadores dedicam todos os seus esforços e que nos dotou de conhecimentos de extraordinária importância a respeito do mecanismo da vida psíquica e das suas perturbações. (Ferenczi, 1993/1918, p. 14).

Ferenczi (1993/1918) alertou sobre a relevância da psicanálise para o entendimento das neuroses e censura os neurologistas, questionando: "Como se deveria conceber o modo de ação dos fatores psíquicos, a psicogênese de quadros clínicos tão graves e que dão uma tal impressão de organicidade?" (Ferenczi, 1993/1921, p. 19). A fim de discutir esta questão, Ferenczi recorre a Charcot, Breuer e Freud para afirmar que o pavor e a lembrança poderiam, sim, provocar sintomas orgânicos. Referindo-se às neuroses de guerra, Ferenczi (1993/1918) apontou para uma predisposição psíquica, predisposição esta ligada a uma "série etiológica". Esta série, sustentada por Freud em "O Inconsciente" (2004/1915), nos ensina que determinada representação, por ter sido recalcada, pode aparecer na consciência vinculada a uma série de representações as quais se manifestam de forma disfarçada. 
Nas neuroses de guerra, Ferenczi (1993/1918) apontou que o traumatismo vivido pelo sujeito figuraria apenas como um facilitador para a ativação dessa "série etiológica", a qual faria a neurose eclodir, de modo disfarçado, através de uma enfermidade orgânica, sem causa orgânica aparente. Mais adiante, afirmou que o sujeito com neurose traumática ou de guerra está fixado no narcisismo, onde o excesso de libido no Eu causaria a neurose. Ele alertou para o fato de que a libido, uma vez entendida no âmbito da erogeneidade, e não simplesmente no âmbito da genitalidade, poderia estar investida também no seu próprio Eu, entendido aqui como um Eu-corporal (Freud, 1996/1923). Freud (2004/1914), no artigo sobre o narcisismo, afirma:

Quanto a um órgão apresentar uma sensibilidade dolorosa sem que tenha ocorrido alteração alguma, encontraremos o protótipo disto no estado de excitação dos órgãos genitais, que apresentam tais características sem estarem propriamente enfermos ... Poderíamos então designar como erogeneidade a atividade que emana de uma parte do corpo e envia estímulos sexualmente excitantes em direção à vida psíquica ... Agora, basta que arrisquemos apenas mais um passo: podemos considerar que a erogeneidade é uma faculdade geral de todos os órgãos e, portanto, nos referir a um aumento ou redução da erogeneidade em determinada parte do corpo. (Freud, 2004/1914, pp. 104-105).

Através desta afirmação, podemos entender quando Ferenczi (1993/1918) afirma que o paciente atingido por uma neurose traumática é afetado, na maioria dos casos, pelo que ele chama de "hipersensibilidade do ego". Esta sensibilidade aparecia quando o paciente retirava sua libido dos objetos externos, concentrando-a toda no Ego. Este fato, por conseguinte, causaria um êxtase de libido nesta instância, provocando sensações orgânicas hipocondríacas e hipersensibilidade. Desse modo, afirma que, quando isso acontece, pode-se dizer que o paciente regrediu ao seu narcisismo infantil, de amor a si mesmo, devido a um enfraquecimento do amor objetal. Assim, um "indivíduo que desde a origem apresenta uma neurose narcísica desenvolverá mais facilmente uma neurose traumática, mas ninguém está inteiramente imune na medida em que o estágio narcísico é um ponto de fixação importante do desenvolvimento libidinal de todo ser humano" (Ferenczi, 1993/1918, p. 26). 
Dessa maneira, Ferenczi (1993/1918) vai além da teoria de Strumpell referente aos benefícios secundários da doença (como pensão, indenização, isenção de serviço ativo), pontuando que a doença, apesar de ter um ganho secundário, teria também um ganho mais importante, um ganho primário, referente ao prazer de se sentir cuidado e protegido no "seguro abrigo da situação infantil, outrora abandonada a contragosto" (Ferenczi, 1993/1918, p. 27). Para ele, o que eclodiria esta neurose seria um afeto demasiado intenso o qual, por não ter sido descarregado por uma via psíquica adequada, encontraria no corpo doente tal satisfação, regredindo ao estágio infantil do narcisismo.

Ferenczi (1993/1917) conceituou as patoneuroses ou neuroses de doença como sendo um resultado de uma doença orgânica que, por ter sido superinvestida de libido, provocaria um recrudescimento local desta. Para ilustrar, alude ao exemplo já mencionado por Freud de uma pessoa que, com dente cariado ou doloroso, retira seu investimento libidinal do mundo externo e passa a concentrá-lo no ponto doloroso do dente. Ressalta que este ponto doloroso, ao mesmo tempo em que causa dor, representa também um ponto de obtenção de prazer, no qual se pode obter satisfações libidinais através de certas ações como o chupar, o empurrar ou mesmo aspirar o dente com a ajuda da língua. A partir disso, afirmou que essas ações, por trazerem prazer ao sujeito, são acompanhadas de uma qualidade genital, ou seja, são genitalizadas. A qualidade genital do órgão lesionado, já aqui citada por Freud, podia, para Ferenczi, acarretar uma perturbação da libido não apenas narcísica, mas, eventualmente, também transferencial (histérica). Ferenczi (1917/1993) denominou essa patologia de histeria da doença ou patohisteria, onde a libido objetal, uma vez preservada, opõe-se à neurose sexual de Freud, em que a perturbação da libido é primária e o distúrbio orgânico, secundário. Salientou ainda que é mais difícil distingui-las dos estados de hipocondria, afirmando que a diferença essencial entre esta, as patoneuroses e a patohisteria é que na hipocondria não existe nem nunca existiu alterações visíveis e detectáveis dos órgãos.

No que diz respeito à neurose traumática, ele nos fala que ela é fruto de um choque psíquico e fisico intenso, sem lesão corporal importante. Nas suas palavras, o sintoma da neurose traumática "com- 
bina a regressão narcísica (abandono de uma parte dos investimentos de objeto) e os sintomas da histeria de conversão ou de angústia, que classificamos, como se sabe, de neuroses de transferência" (Ferenczi, $1993 / 1917$, p. 295). No entanto, ao se deparar com tantas categorias de neurose, Ferenczi chega a se perguntar como uma doença ou ferimento pode provocar uma neurose narcísica, "um narcisismo de doença" (Ferenczi, 1993/1917, p. 295), ou melhor, uma patoneurose.

Ferenczi (1993/1917) nos adverte que a libido, justamente por não ser dividida igualmente em todo o corpo, pode ficar concentrada ou condensada em zonas erógenas específicas do mesmo. Este fato faz com que a zona erógena mais investida sofra uma tensão mais forte em relação às outras partes do corpo, causando, portanto, uma doença. Assim, da mesma forma, o ferimento ou lesão em uma dessas partes do corpo, sem dúvida, acarretará um distúrbio na libido mais grave do que em outras partes não tão investidas. Porém, vale ressaltar que as patoneuroses, ao mesmo tempo em que prejudicam o paciente, colocam-no perante uma condição de restabelecimento, no sentido de que a doença, no momento em que paralisa o sujeito, faz com que o mesmo seja convocado a redistribuir essa libido.

Nota-se que ao propor a patoneurose como uma nova categoria de neurose, Ferenczi afirmou que ela estaria localizada entre a histeria e outras disfunções orgânicas. Casetto (2006, p. 125), ao dizer que: "nessa categoria estariam as neuroses atuais, certas doenças como a asma nervosa, as neuroses do estômago, as neuroses cardíacas, a enxaqueca etc.", salienta que as formulações de Ferenczi refletiram um considerável avanço teórico diante da teoria de Groddeck. Uma vez se centrando na distribuição libidinal no adoecimento de um órgão, ele não atribuiu um determinismo psíquico direto às afecções, como o fez Groddeck. Além disso, Ferenczi pôde entender o aparecimento de certas lesões a partir do processo analítico. Para ele, no momento em que o investimento libidinal fosse melhor distribuído, a vida afetiva do paciente podia ser restabelecida.

Dito isso, concordamos com Casetto (2006) quando pontua que apesar de Ferenczi não ter avançado nessa temática tal como Freud o fez (através das neuroses atuais e sua comparação com o funcio- 
namento das psiconeuroses), ele deixou consideráveis contribuições criando conceitos para determinadas afecções orgânicas, idealizando perspectivas clínicas e atribuindo a elas um estatuto importante no campo da psicanálise. Salienta, ainda, que o fato de ter sido Húngaro possa ter criado um terreno fértil para que, depois, Franz Alexander, de mesma nacionalidade, construísse teorizações que também marcaram o território de saber da "psicossomática".

\section{A corrente americana e o Instituto de Psicossomática de Chicago}

O resgate da expressão "psicossomática", antes inaugurada por Heinroth, foi feito justamente por um médico da corrente americana, Félix Deutsch (1894-1963), em 1926. Este, apontando para a utilização indiscriminada da noção psicanalítica de conversão, criticou a maneira organicista da medicina, a qual, por se voltar à descrição dos sintomas, ignorava a subjetividade no aspecto do adoecer (Volich, 2000).

Félix Deutsch fundou a Associação Psicanalítica de Boston e incitou nos hospitais uma discussão acerca da relação transferencial médico-paciente, onde formulou o método da anamnese associativa. Este método, aplicado até hoje pela medicina, consiste em um interrogatório específico dirigido ao paciente e se baseia não apenas nos sinais físicos manifestados. Isso permitia ao médico adentrar na esfera psicodinâmica do paciente e entender o motivo pelo qual este manifestava determinada doença (Volich, 2000). Esta experiência fez com que Deutsch contribuísse de modo significativo com os trabalhos de Franz Alexander (1891-1964) e Helen Flanders Dunbar (1902-1959), nomes que mais se destacaram na criação da medicina psicossomática americana. De acordo com Ramos (1994), apesar das contribuições de Deutsch para o campo da medicina psicossomática e psicanalítica na América, foi Helen Dunbar, idealizadora e fundadora da Sociedade Americana de Psicossomática, quem ofereceu sua base teórica fundamental. Dunbar publicou o livro "Mudanças emocionais e biológicas: uma pesquisa da literatura sobre as inter-relações psicossomáticas", onde identifica traços comuns de personalidade em pacientes com 
diferentes patologias, tomando como norte um protocolo complexo de informações e características individuais.

As ideias de Dunbar, por sua vez, influenciaram significativamente as formulações de Franz Alexander no que se refere aos perfis psicossomáticos específicos para cada tipo de doença. Contudo, apesar de tal influência, Alexander posicionou-se criticamente com relação às teorizações de Dunbar. Assim, aponta para a descrição de perfil do paciente coronariano formulada por Dunbar:

Segundo Dunbar, tal paciente é geralmente uma pessoa permanentemente batalhadora, com grande controle e persistência, visando ao sucesso e à realização. Ele planeja a longo prazo; tem, frequentemente, uma aparência distinta. Ele exibe, em alto grau, o que Freud chamou de "princípio da realidade", a capacidade de adiar e subordinar ações a objetivos a longo prazo. (Alexander, 1989, p. 59).

Esta descrição foi bastante criticada por Alexander, pois, para ele, a frequência estatística de traços de personalidade associada às doenças não poderia significar o mesmo que relação causal. Segundo Alexander (1989), a relação deveria ser feita a partir de certos estados emocionais, mais especificamente com determinados tipos de conflitos que, sendo reprimidos, provocariam a cronificação de alterações fisiológicas, normalmente acompanhadas de emoções. Tais alterações, por regularem a expressão das emoções, faziam com que elas desaparecessem.

Influenciado pelo pensamento de Deutsch sobre a medicina do homem total e inspirado em sua crítica aos perfis psicossomáticos de Dunbar, Alexander (1989) parte da concepção da existência de um organismo enquanto unidade, propondo que toda doença é psicossomática, na medida em que as emoções intensas exercem grande influência sobre as funções do corpo. Ao afirmar que "cada situação emocional corresponde uma síndrome específica de alterações físicas, psicossomáticas, tais como o riso, o choro, o enrubescimento, alterações da frequência cardíaca, da respiração, etc." (Alexander, 1989, p. 50), ele apontou que as desordens crônicas do corpo podem se desenvolver sob a influência de transtornos emocionais prolongados. 
Em Chicago, Franz Alexander e colaboradores destacaram-se nas pesquisas relacionadas às interações corpo e psiquê, disponibilizando tratamento psicanalítico a pacientes com doenças fisiológicas diversificadas. Estudaram basicamente as seguintes patologias: a úlcera duodenal, a colite ulcerativa, a asma brônquica, a neurodermatite, a hipertensão essencial, a artrite reumatoide e a tireotoxicose. Estas doenças seriam resultado de uma desordem fisiológica, causada por algum tipo de manifestação psíquica. Entretanto, apesar de considerar que os aspectos emocionais poderiam interferir diretamente no fator orgânico, Alexander fez questão de deixar claro a diferença entre uma histeria de conversão e uma "neurose orgânica". Aliás, de acordo com Birman (1980), Alexander e seus colaboradores foram os primeiros a retomar esta diferenciação realizada por Freud. Em um capítulo à parte, denominado "Histeria conversiva, neurose vegetativa e distúrbio orgânico psicogênico", Alexander (1989) diferencia aquilo que seria da ordem de uma histeria conversiva, de um distúrbio orgânico psicogênico. Ao afirmar que certas desordens vegetativas de órgãos internos não poderiam ser expressas simbolicamente, como na histeria, ele pontua:

É pouco provável, no entanto, que órgãos internos como o fígado ou as arteríolas pequenas do rim possam simbolicamente expressar ideias. Isto não significa que eles não possam ser influenciados por tensões emocionais, que podem ser conduzidas a qualquer parte do corpo por meio da via cortico-talâmica e do sistema nervoso autônomo. Sem dúvida, influências emocionais podem estimular ou inibir a função de qualquer órgão. Depois que a tensão emocional relaxa, as funções corporais voltam a seu equilíbrio normal. Sempre que a estimulação ou inibição emocional de uma função vegetativa torna-se crônica e excessiva, a ela nos referimos como "neurose orgânica". (Alexander, 1989, pp. 36-37).

O autor ressaltou que uma histeria de conversão é incapaz de causar tanto estrago em determinado órgão, tal como pode acontecer em uma "neurose orgânica". No que se refere a esta última, ele salientou que uma neurose deste tipo, diferentemente de uma conversão, manifesta-se não na tentativa de expressar uma emoção, mas sim em detrimento de uma resposta fisiológica dos órgãos vegetativos a estados emocionais, os quais, sendo ou não constantes, sob a influência 
de uma raiva ou frustração, apareceriam periodicamente. A referida resposta seria um modo de adaptação e restabelecimento do corpo, quando este se prepara para se deparar com um evento conflitante. As neuroses deste tipo foram classicamente enquadradas como "psicossomáticas", devido ao caráter de cronicidade dos sintomas, os quais, por sua vez, seriam acompanhados, de forma proporcional, por uma persistência na "vontade" emocional. Assim, a persistência em "atitudes de rivalidade, agressividade e hostilidade excitaria o sistema nervoso simpático adrenérgico, produzindo enxaquecas, hipertensão, hipertiroidismo, neurose cardíaca, artrite, depressão e diabetes" (Volich, 2000, p. 96).

Fundamentando-se na teoria ferencziana sobre a "neurose de órgão" e na concepção da "termodinâmica energética emocional" de Dunbar, Alexander (1989) idealizou o conceito de "constelação psicodinâmica específica". Esta teoria consiste no fato de que as diversas respostas fisiológicas aos estímulos emocionais, normais e mórbidos, têm sua variação conforme a origem do estado emocional desencadeante. Ao afirmar que cada estado emocional tem sua própria síndrome fisiológica, o autor salientou que o conteúdo psicológico, junto à configuração dinâmica de cada força psicológica motivadora, determina funções biológicas que serão ativadas ou inibidas. No que tange a essas forças, afirmou que influências como a ansiedade, os impulsos eróticos e hostis reprimidos, a frustração ou os anseios dependentes, os sentimentos de culpa e de inferioridade, estariam presentes em todos os distúrbios neurovegetativos. Por esta razão, precisariam ser discriminados segundo uma configuração específica na qual eles aparecem. Ao comparar a configuração psicodinâmica específica com a estereoquímica, ele afirma:

Os mesmos átomos: carbono, hidrogênio, oxigênio e nitrogênio, entram na constituição dos diferentes compostos orgânicos; porém, estes átomos estão combinados numa grande variedade de padrões estruturais e cada combinação representa uma substância de qualidade bastante específica. A hostilidade pode ser expressa pelo ataque físico, seja este através de extremidades ou de atos de sujar, cuspir, etc., ou por insultos verbais, fantasias destrutivas ou modos de ataques menos diretos. As respostas fisiológicas sofrerão a devi- 
da variação. O desejo de ser cuidado, como é visto nas retrações vegetativas, pode aparecer como o desejo de ser nutrido, acariciado, carregado, satisfeito, elogiado, encorajado ou ajudado pelos outros de vários modos. (Alexander, 1989, p. 57).

Através desta analogia, explicou que é possível entender como determinadas forças psicológicas podem interferir em certos distúrbios orgânicos ou neurovegetativos. Analisando as diferentes combinações, Alexander e colaboradores chegaram, por exemplo, a constatação de que pacientes afetados por disfunções gástricas são influenciados por preocupações, medos, brigas de família e contratempos nos negócios. Ressaltou que o denominador comum nestas tensões emocionais é um intenso desejo de repouso, segurança e ajuda. Sobre os pacientes atingidos por uma diarréia crônica, colite espástica e colite mucosa, afirmaram que estes revelam um conflito pautado nos seus fortes desejos receptivos e exigentes (orais-agressivos). Estes pacientes tentariam compensar estes desejos pela atividade e o impulso de dar, substituindo a realização e a doação verdadeiras por ataques de diarréia. Já no que diz respeito ao perfil psicológico do paciente asmático, observa-se que "o fator psicodinâmico nuclear é um conflito centralizado numa dependência excessiva e não resolvida da mãe" (Alexander, 1989, p. 104).

Verifica-se, contudo, que apesar de Alexander ter afirmado que não há como traçar um perfil característico para certas afecções, criticando inclusive as posições de Dunbar, é justamente isso que ele insiste em fazer. Embora tenha se baseado na teoria psicanalítica, é possível observar que a corrente americana de psicossomática, na interseção medicina e psicanálise, aproximou-se mais do campo de saber da medicina, atribuindo perfis psicológicos e generalizando a subjetividade, o que não é nem nunca foi a proposta da psicanálise. A seguir, através das formulações do Instituto de Psicossomática de Paris, veremos teorizações organizadas segundo a estrutura psíquica do doente.

\section{Pierre Marty e o Instituto de Psicossomática de Paris}


Entre os anos de 1950 e 1963, entrou em destaque a corrente francesa de psicossomática, liderada principalmente pelos psicanalistas Pierre Marty (1918-1993) e Michel de M’Uzan. Estes, juntamente com Michel Fain e C. David, criaram o Instituto de Psicossomática de Paris (IPSO), onde se praticam até hoje pesquisas e tratamentos em pacientes que apresentam distúrbios do tipo "psicossomático" (Casetto, 2006).

Em 1962, Marty e M'Uzan construíram o conceito de pensamento operatório. Este conceito, idealizado entre 1958 e 1962, foi fruto de estudos realizados pelo Instituto de Psicossomática de Paris e resultou na publicação do livro "A investigação psicossomática" (Marty \& M'uzan, 1994/1963). Exposto por Marty e M. de M'Uzan no XXIII Congresso de Psicanálise dos países de língua francesa, em 1982, o conceito de pensamento operatório encontra sua origem na concepção freudiana acerca das organizações narcísicas, ou seja, como doenças que afetam o Eu. A noção de pensamento operatório apontava para uma conceituação inédita de uma forma de atividade psíquica distinta da neurose e da psicose. "Ela descrevia um modo de pensamento consciente que parecia despojado de espessura, de duplos sentidos, de metáforas, de atos falhos, enfim, de atravessamentos pela fantasia" (Casetto, 2006, p. 129). Por este motivo, a análise desses pacientes se daria, para Marty, com grande dificuldade. Para Casetto (2006), de acordo com a IPSO, tais pacientes teriam dificuldade de se deixar levar pela regra fundamental da associação livre, pois uma vez não apresentando uma demanda de análise, os relatos tenderiam sempre a estar vinculados às experiências objetivas do cotidiano. $\mathrm{O}$ pensamento operatório se definiria, então, por uma precariedade na atividade do pensamento, manifestando-se por meio de uma pobreza na simbolização e na verbalização, ocasionada pelo déficit nas representações psíquicas destes pacientes. A lesão psicossomática, devido a uma falha na atividade psíquica, não seria capaz de promover o processo de elaboração psíquica através dos sintomas psiconeuróticos, dos atos falhos e dos sonhos.

Conforme Marty (1993), o aparelho psíquico do paciente psicossomático apresentaria uma falha de ligação, no nível das representações, onde as excitações somáticas seriam impedidas de alcançar a esfera das representações psíquicas. A pobreza psíquica, no âmbito 
das representações, levariam o paciente psicossomático a desenvolver o que chamou de Depressão Essencial. Este conceito foi centrado na idéia de que os pacientes acometidos de lesões somáticas crônicas apresentariam uma carência psíquica que precisaria ser reparada. De acordo com Vieira (1997), a Depressão Essencial se caracteriza como um estado clínico no qual há um rebaixamento do tônus libidinal, um desinvestimento pelos objetos do mundo externo. Isto, por sua vez, refletia uma verdadeira atitude de indiferença com relação aos fatos, pessoas e coisas que rodeiam esses pacientes. A doença somática entraria para sinalizar esta carência de investimento nos objetos externos, motivada por uma estrutura psíquica pobre de fantasias e de palavras.

Tal carência de investimento nos objetos externos, Marty localiza a questão do déficit como um elemento que marca a disposição clínica fundamental nestes pacientes. A lesão de órgão resultaria desse déficit na esfera psíquica. Este déficit, por conseguinte, causaria uma desordem econômica libidinal, provocando um aumento de libido em determinado órgão, no caso do "paciente psicossomático", no órgão afetado. Em detrimento disso, Marty (1993) localiza esses pacientes em uma classificação separada dos pacientes psiconeuróticos. Diferentemente das psiconeuroses (histeria, fobia, obsessões), nas "afecções psicossomáticas" o inconsciente não entra em questão, na medida em que tais afecções não estão encadeadas à série de representações psíquicas inconscientes. Assim, o autor classifica tais afecções como lesões resultantes do plano pré-consciente, sob a ótica de uma falha nas mentalizações. A falha na mentalização referia-se à incapacidade do aparelho psíquico de realizar elaborações em um nível além da doença descarregada no corpo.

Para Marty (1993), os psiconeuróticos seriam sujeitos capazes de suportar uma determinada carga de excitação somática pela esfera psíquica, conseguindo administrá-las e descarregá-las através de um sintoma, resultado de um trabalho psíquico. Já os sujeitos acometidos de transtornos somáticos, que apresentam um discurso operatório, seriam incapazes de produzir sintomas inconscientes, devido ao empobrecimento no alcance das representações psíquicas, motivo pelo qual o autor os denominou de "neuróticos mal mentalizados". 
Seguindo este ponto de vista, Marty (1988) categorizou quatro tipos distintos de neurose: as neuroses mentais clássicas, as neuroses de comportamento, as neuroses de mentalização incerta e as neuroses mal mentalizadas. As primeiras, o autor atribuiu um bom nível de mentalização, uma vez que seriam capazes de proteger o sujeito contra as excitações somáticas através da simbolização. Nas segundas, os sujeitos lançam mão do próprio comportamento para expressar as várias excitações internas e externas as quais são submetidos. Nas neuroses de mentalização incerta, observou variações substanciais na quantidade de representações. Já nas neuroses mal mentalizadas, verificou sujeitos com intensa precariedade discursiva diante da escuta clínica, supondo-se, portanto, uma pobreza no campo mental e representativo. Considerando os quatro tipos distintos de neurose propostos por Marty (1988) e Volich (2000), nos coloca que as referidas neuroses eclodem de acordo com os "recursos mais evoluídos" do paciente. Em razão do constante afluxo de excitações e da necessidade de descarregá-las, o sujeito encontra fundamentalmente três vias: "a via orgânica, a ação e o pensamento, que, nessa ordem, representam o grau hierárquico progressivo da evolução dos recursos do indivíduo para responder aos estímulos, internos ou externos, aos quais é submetido" (Volich, 2000, p. 147). Por conseguinte, fazendo um paralelo, podemos dizer que a via orgânica seria o meio pelo qual o neurótico mal mentalizado descarregaria a excitação, eclodindo, assim, uma doença. Entretanto, cada uma das vias para lidar com o sofrimento não seria escolhida pelo sujeito por acaso, mas sim por uma questão de evolução: o sujeito escolhe o recurso mais evoluído para atingir sua satisfação e aliviar a tensão libidinal.

Desse modo, têm-se que a falha na mentalização leva o sujeito a recorrer a vias mais primitivas para atingir sua satisfação libidinal ou pulsional. Primitivas no sentido de menos evoluídas, pois uma vez que o indivíduo for incapaz de elaborar tais excitações pela via psíquica, ele "prefere" descarregar no próprio corpo estas excitações, assim como um bebê que, por não possuir aparato nem físico nem psíquico para administrar suas exigências orgânicas, não consegue tolerá-las e acaba indo por um caminho do reflexo ou de reações involuntárias para atingir sua satisfação. Não foi à toa que Marty (1988) desenvolveu sua teoria a respeito da falha nas mentalizações a partir 
das relações mãe-bebê no desenvolvimento infantil, atribuindo a esta falha um resultado de uma falha anterior na função materna.

Ao considerar a falha na função materna como o maior desencadeador de uma falha nas mentalizações, Marty (1988) salienta que a incapacidade da mãe em oferecer ao seu bebê os cuidados fundamentais é o que determina um desenvolvimento posterior de uma "doença psicossomática". Assim, as excitações que outrora foram sentidas na infância, por não terem sido direcionadas a um objeto ou satisfeitas através dos cuidados maternos, são na idade adulta escoadas para o plano somático, ao invés do psíquico. Percebe-se que ao evidenciar o desvio inadequado de excitação, Marty, de certa forma, baseou-se na teoria freudiana das "neuroses atuais", em especial da neurose de angústia. Ao se utilizar do ponto de vista econômico para explicar as afecções psicossomáticas, ele nos diz que tal desordem na relação tensão-satisfação de libido se deve ao traumatismo: "os traumatismos se definem pela quantidade de desorganização que produzem e não pela qualidade do acontecimento ou da situação que os produzem" (Marty, 1988, p. 53).

No momento em que vincula a questão do traumatismo a um fator meramente econômico, no sentido de um transbordamento de libido pela via somática, Marty (1993) delimita a diferença entre as lesões psicossomáticas e o sintoma histérico. Ele nos diz que, no sintoma, não há um transbordamento de libido pela via somática, na medida em que as excitações que demandam descarga ao sujeito se ligam às representações psíquicas e, portanto, são elaboradas e trazem consigo um sentido que, através da associação livre subsidiada pela transferência, pode ser decifrado e, portanto, interpretado. No caso das afecções psicossomáticas, em detrimento do afeto sexual não ter passado por um processo de ligação no psiquismo, isso coloca os pacientes acometidos por estas afecções numa posição de inacessibilidade ao tratamento analítico.

Confrontados com este fato, Marty e colaboradores da IPSO vislumbraram uma intervenção particular para atender casos desse tipo. Para eles, o analista deve assumir uma função de pára-excitação materna diante do paciente, no intuito de provocar uma redistribuição 
libidinal e uma possível ligação com as representações psíquicas (Volich, 2000).

\section{Para concluir}

Freud, ao olhar o corpo para além da sua materialidade anatômica, atribuindo-lhe um caráter erótico e sexual, elaborou um importante arcabouço teórico sobre as afecções orgânicas sem uma etiopatogenia geral, abrindo um terreno fértil para instauração de um campo novo de investigação: a psicossomática. Sabemos que ao longo de sua obra Freud abandonou seu interesse em relação às "neuroses atuais", priorizando o aspecto concernente à teoria do recalque e da sexualidade infantil, especialmente vinculada às psiconeuroses histérica, obsessiva e fóbica. Todavia, apesar das formulações de Freud sobre as "neuroses atuais" tenham sido deixadas de lado por ele próprio ao longo do seu percurso, elas ainda guardam uma grande relevância teórica e conceitual, posto que conduzem as "contribuições modernas sobre a psicossomática” (Laplanche \& Pontalis, 1986/1967, p. 384).

No texto Moral sexual 'civilizada' e doença nervosa moderna, Freud (1996/1908) apontou que uma satisfação sexual inadequada seria o grande responsável pelas enfermidades nervosas. O curioso é que nos Três ensaios sobre a teoria da sexualidade, de 1905, Freud já apontara à existência de uma sexualidade infantil, perversa e poliforma reprimida, ou seja, que a sexualidade humana não está a serviço da procriação e sim da obtenção de prazer (Freud, 1996/1905). Em outras palavras, ele quis salientar que o sujeito vive em função de obter prazer para aliviar a tensão libidinal. Esse princípio homeostático, o qual Freud esteve tão vinculado no começo de sua obra, foi um resquício do modelo econômico usado por ele para explicar o surgimento dos sintomas das "neuroses atuais". Observa-se a influência do modelo econômico especialmente nos pensamentos de Ferenczi, nas contribuições da Corrente Francesa de psicossomática (com Marty e M’Uzan), bem como da Americana. Deste modo, resguardadas as distinções entre as contribuições de cada autor ou grupo mencionado, o que se verifica em todos eles é a pers- 
pectiva de conceber um corpo pulsional, que pode se prestar a certa complacência somática e à descarga de energia libidinal inapropriada.

Desta forma, resgatar historicamente algumas principais teorizações produzidas a partir de Freud teve, portanto, seu caráter político, especialmente em meio ao movimento do DSM, principalmente com a emergência de sua terceira edição, de expurgar qualquer resquício do vocabulário psicanalítico. Mostrar as importantes contribuições teóricas que envolvem a psicossomática é uma tarefa que resiste, portanto, a homogeneização do saber, tal como propõe o DSM sob o bojo da palavra "transtorno".

\section{Referências bibliográficas}

Alexander, F. (1989). Medicina Psicossomática. Porto Alegre, Brasil: Artes Médicas. American Psychiatric Association (APA). (2002). Manual Diagnóstico e Estatístico de Transtornos Mentais: DSM-IV-TRTM: texto revisado. Porto Alegre, Brasil: Artmed.

American Psychiatric Association (APA). (2014). Manual Diagnóstico e Estatístico de Transtornos Mentais: DSM-V. 5. Porto Alegre, Brasil: Artmed.

Berrios, G. \& Mumford, D. (2012). Transtornos somatoformes - Seção clínica. In: G. Berrios \& R. Porter (Orgs.). Uma história da psiquiatria clínica - III (pp. 729-762). São Paulo, Brasil: Escuta.

Birman, J. (1980). Enfermidade e loucura: Sobre a medicina das inter-relações. Rio de Janeiro, Brasil: Campus Ed.

Casetto, S. J. (2006). Sobre a importância do adoecer: uma visão em perspectiva da psicossomática psicanalítica do século XIX. Psyquê, 10(17), 121142. Disponível em: http://pepsic.bvsalud.org/scielo.php?script=sci_ arttext\&pid=S1415-11382006000100008.

Dunker, C. \& Kyrillos Neto, F. (2011). A crítica psicanalítica do DSM IV. Breve história do casamento psicopatológico entre psicanálise e psiquiatria. Revista Latinoamericana de Psicopatologia Fundamental (Dezembro 2011), 611-626. Disponível em: http://www.scielo.br/pdf/rlpf/v14n4/ v14n4a03.pdf.

Ferenczi, S. (1993/1917). As patoneuroses. In: Ferenczi, S. Obras completas (Vol. 3, pp. 291-300). São Paulo, Brasil: Martins Fontes. 
Ferenczi, S. (1993/1918). Dois tipos de neurose de guerra (histeria). In: Ferenczi, S. Obras completas (Vol. 2, pp. 293-310). São Paulo, Brasil: Martins Fontes.

Ferenczi, S. (1993/1921). George Groddeck: O explorador de almas. In: Ferenczi, S. Obras completas (Vol. 3, pp. 161-165). São Paulo, Brasil: Martins Fontes.

Freud, S. (1996/1895[1894]). Sobre os fundamentos para destacar da neurastenia uma síndrome específica denominada "neurose de angústia". In: S. Freud, Edição standard brasileira das obras psicológicas completas de Sigmund Freud (J. Salomão, trad., Vol. 3, pp. 91-118). Rio de Janeiro, Brasil: Imago.

Freud, S. (1996/1905). Três ensaios sobre a teoria da sexualidade. In S. Freud, Edição standard brasileira das obras psicológicas completas de Sigmund Freud (J. Salomão, trad., Vol. 7, pp. 119-127). Rio de Janeiro, Brasil: Imago.

Freud, S. (1996/1908). Moral sexual 'civilizada' e doença nervosa moderna. In: S. Freud, Edição Standard Brasileira das Obras psicológicas Completas de Sigmund Freud (J. Salomão, trad., Vol. 9, pp. 167-186). Rio de Janeiro, Brasil: Imago.

Freud, S. (1996/1923). O ego e o id. In S. Freud, Edição standard brasileira das obras psicológicas completas de Sigmund Freud (J. Salomão, trad., Vol. 19, pp. 13-80). Rio de Janeiro, Brasil: Imago.

Freud, S. (2004/1914). À Guisa de Introdução ao Narcisismo. In: Freud, S. Obras Psicológicas de Sigmund Freud Escritos sobre a Psicologia do Inconsciente. (Luiz Alberto Hanns, trad., Vol. 1, pp. 95-131). Rio de Janeiro, Brasil: Imago.

Freud, S. (2004/1915). O Inconsciente. In: Freud, S. Obras Psicológicas de Sigmund Freud Escritos sobre a Psicologia do Inconsciente. (Luiz Alberto Hanns, trad., Vol. 2, pp. 13-74). Rio de Janeiro, Brasil: Imago.

Groddeck, G. (1992/1920). Estudos psicanalíticos sobre psicossomática. São Paulo, Brasil: Perspectiva.

Groddeck, G. (1997/1923). O Livro dIsso. São Paulo, Brasil: Perspectiva.

Groddeck, G. (1997/1917). O homem e seu Isso. São Paulo, Brasil: Perspectiva.

Lacan, J. (2001/1966). O lugar da psicanálise na medicina. Opção lacaniana, $32,8-14$.

Laplanche, J. \& Pontalis, J-B. (1986/1967). Vocabulário da psicanálise. São Paulo, Brasil: Martins Fontes.

Marty, P. (1993). A psicossomática do adulto. Porto Alegre, Brasil: Artes Médicas.

Marty, P. \& M'uzan, M. (1994/1963). O pensamento operatório. Revista Brasileira de Psicanálise, 28, 165-74.

Marty, P. (1988). Mentalização e psicossomática. São Paulo, Brasil: Casa do psicólogo. 
Pereira, M. (1996). Questões preliminares para um debate entre a psicanálise e a psiquiatria no campo da psicopatologia. In: Couto, Luiz Flávio Silva (Org.). Pesquisa em psicanálise (pp. 43-54). Belo Horizonte, Brasil: SEGRAC.

Quintella, R. (2005). A psicossomática nos confins de sentido - problemas e reflexões psicanalíticas do fenômeno psicossomático. Dissertação de mestrado não publicada. Universidade do Estado do Rio de Janeiro. Recuperado em http://teopsic.psicologia.ufrj.br/arquivos/documentos/4CF0E4C D6EF91635F26D919ADBA500BC.pdf.

Rinaldi, D., Nicolau, R. F. \& Pitanga, C. E. (2013). Do fenômeno psicossomático ao sintoma: a aderência do sujeito ao diagnóstico médico e o trabalho analítico. Ágora: Estudos em Teoria Psicanalítica, 16(spe), 95-108.

Shorter, E. (2012). Transtornos somatoformes - Seção social. In: G. Berrios \& R. Porter (Orgs). Uma história da psiquiatria clínica - III (pp. 763-781). São Paulo, Brasil: Escuta.

Vieira, W. (1997). A psicossomática de Pierre Marty. In: Ferraz, F.C. \& Volich, R.M. (Orgs.) Psicossoma I (pp. 15-22). São Paulo, Brasil: Casa do Psicólogo.

Volich, R. (2000). Psicossomática. São Paulo, Brasil: Casa do Psicólogo. 